San Jose State University

SJSU ScholarWorks

Faculty Publications, Sociology

Sociology and Interdisciplinary Social Sciences

January 1992

\title{
Four Approaches to Using Patients to Teach and Evaluate Clinical Skills of Residents, Interns, and Students
}

\author{
F. Medio
}

Stephen J. Morewitz

San Jose State University, stephen.morewitz@sjsu.edu

Follow this and additional works at: https://scholarworks.sjsu.edu/sociology_pub

Part of the Sociology Commons

\section{Recommended Citation}

F. Medio and Stephen J. Morewitz. "Four Approaches to Using Patients to Teach and Evaluate Clinical Skills of Residents, Interns, and Students" Journal of the American Osteopathic Association (1992): 1433-1436.

This Article is brought to you for free and open access by the Sociology and Interdisciplinary Social Sciences at SJSU ScholarWorks. It has been accepted for inclusion in Faculty Publications, Sociology by an authorized administrator of SJSU ScholarWorks. For more information, please contact scholarworks@sjsu.edu. 


\title{
Four approaches to using patients to teach and evaluate clinical skills of residents, interns, and students
}

\author{
FRANKLIN J. MEDIO, PhD \\ STEPHEN J. MOREWITZ, PhD
}

As osteopathic medical educators look for ways to enhance their training programs in a fiscally responsible manner, previously underused training methods deserve a second look. This article presents four ways that patients can serve as teachers and evaluators of residents' and students' clinical skills.

(Key words: Osteopathic medical education, graduate medical education, patient participation, patient education)

Traditionally, patients have played a limited - but central- role in the education of osteopathic medical students, interns, and residents. Specifically, the patients' role has been passive; they are "objects" of study, rather than active participants in the teaching process. But their role canand should-change. Four ways that patients can serve as teachers and evaluators of residents', interns', and students' clinical skills are outlined herein. All of these approaches can be implemented at minimal costs to osteopathic medical colleges and residency programs.

At the time that this article was written, Dr Medio was director of educational resources at the University of Medicine and Dentistry-School of Osteopathic Medicine, Stratford, NJ. Currently, he is project manager, Department of Outcomes Research and Development, Joint Commission on Accreditation of Healthcare Organizations, Oakbrook Terrace, Ill. Dr Morewitz is an assistant professor, Department of Family Practice, College of Medicine, University of Illinois at Chicago.

Reprint requests to Franklin J. Medio, PhD, Joint Commission on Accreditation of Healthcare Organizations, One Renaissance Blvd, Oakbrook Terrace, IL 60181.

\section{Bedside teaching rounds}

At the turn of the century, William Osler, MD, stated, "It is truly at the bedside that the young physician learns not only how to solve the patient's problem, but also how to relate to the patient." 1 Unfortunately, studies show that the amount of bedside teaching has declined significantly despite the educational benefits derived during the bedside encounter. ${ }^{2-5}$ Bedside teaching allows residents, interns, and students to question the patient directly; to demonstrate their skills in interviewing and performing a physical examination; to manage the patient's treatment course; and to recognize the patient's psychosocial state.

To be an effective learning experience, bedside teaching must include patient feedback. This feedback gives information on how the patient responds to a physical examination; the patient's perception of the residents', interns', and students' interviewing and interpersonal skills; and how the patient feels physically and psychologically. It is important to note, however, that several potential barriers can inhibit teaching and learning in this situation, and they should be avoided. These potential barriers include:

\section{Bedside visits as 'maintenance checks'}

Bedside visits that are primarily "maintenance checks" or "updates" do not promote learning. A bedside visit needs to be a structured opportunity for teaching and learning that follows a set of already established educational objectives. The attending physician should identify specific learning objectives, focused on one or two key teaching points. 


\section{Poor communication}

Once these educational objectives are established, the next step is to avoid communication problems that may impede learning during bedside teaching rounds. These communication difficulties not only reduce the effectiveness of teaching rounds, but they may also seriously impair assessment, treatment, and relations between the patient and the physician.

Sometimes, a patient may appear reticent to discuss his or her health problems. Likewise, residents, interns, or students themselves may be hesitant in discussing the patient's problem. Rather than attributing this communication difficulty to "patient resistance," physicians-in-training would do well to explore with the patient the reason(s) why he or she is reluctant to reveal personal information. As part of their educational training, the residents, interns, and students might discuss with each other-as well as their trainers-the difficulties they face when they encounter such uncommunicative patients, in addition to any communication problems that may arise with patients who have specific illnesses. Too often, physicians-in-training avoid such situations because they feel uncomfortable, but these situations provide many opportunities for learning.

Patients and their family members may feel left out of the discussion during these bedside visits; they feel "exploited" by the teaching process. Some patients have reported feeling like a "specimen" when the attending physician, residents, and students are standing by their bedside talking about their illness without making eye contact with the patient or family members. Furthermore, using the third person in the patient's presence ("The patient has an acute case of ...") makes the patient feel "used."

Likewise, patients feel uncomfortable when hospital personnel address them by their first name or by using an endearing term, such as "dear." Rather than fostering a personal relationship, such appellations are perceived as unprofessional and as unwanted intrusions into the patient's privacy.

By their behavior-eliciting direct feedback from patients and making a conscious effort to avoid the aforementioned communication pitfalls-clinicians can teach good bedside skills and serve as role models for physicians-in-training.

Another way to enhance communication and to make the patient feel at ease and in control of the situation is to invite questions. Depending on their nature, these questions provide a teaching opportunity for the residents, interns, and students. Such questions also recognize the patient's right to participate in his or her own care.

\section{Round-table seminar}

As a complement to bedside teaching, a round-table seminar format offers residents, interns, and students the opportunity to discuss skills that can improve communication during stressful patient encounters. Participants can learn the social and emotional status of patients who have terminal illnesses, who have lost a limb, or who have experienced some other traumatic event. In addition, family members of patients who have recently died may be the guest speaker.

This format allows residents, interns, and students to deal candidly and openly with stressful situations, without the pressure of the clinical environment. In a more relaxed setting such as that surrounding the round-table seminar, participants get a chance to ask patients a wide range of questions. ${ }^{6}$

A current or former patient who is willing and able to tell participants what it is like to be a patient can be invited to speak at a round-table seminar. However, patients who may be traumatized by recounting their experiences should not be selected. A "unique" speaker is a physician who was hospitalized as a patient. This person sees the experience "from both sides of the fence"-as patient and physician.

The program director or designated faculty member must select and invite the patient to participate in the round-table seminar. Ground rules need to be set in advance. First, the program director or selected faculty member should moderate the discussion. The moderator should introduce the patient, the topic, and the issues. This individual should also provide a brief synopsis of the clinical scenario, including the patient's background information.

Second, the moderator should inform the patient that he or she has the right to refuse to answer any question. Third, the moderator should focus the discussion on the patient's experiences, emphasizing the psychosocial aspects. Participants should try to understand the patient's perspective and feelings while refraining from making any moral or social judgments. 
Finally, enlisting other specialists (medical and nonmedical) as codiscussants can provide residents, interns, and students with key information concerning other healthcare providers' role in caring for patients.

\section{Standardized patients}

The standardized patient is an innovation in medical education pioneered by Drs Harold Barrows, Paula Stillman, and David Kretchmar. ${ }^{7-9} \mathrm{~A}$ recent survey of 136 US medical schools ${ }^{10}$ found that $70 \%$ of them reported using standardized patients for medical student education and resident training. Either symptomatic or asymptomatic, standardized patients can portray a particular patient scenario. They are also trained as teachers in that they can provide focused feedback on clinical skills, such as interviewing techniques and physical diagnostic skills. The director of medical education (DME) may hire an experienced $\mathrm{PhD}$ or physician-consultant to train these patients. Another option is to send such patients to a university-affiliated training center. If so inclined, the DME may personally train these patients.

In a sample scenario, a standardized patient with a history of headaches is examined by the residents, interns, or students. In another scenario, residents may learn the appropriate techniques for examining the lungs and distinguishing among the various pulmonary sounds present in a standardized patient with chronic obstructive pulmonary disease. They may also describe the pertinent positive findings of such an examination.

In both scenarios, the standardized patient provides constructive, detailed feedback concerning the residents' skills in taking a history and performing an examination.

Various investigators ${ }^{11,12}$ have reported that standardized patients can offer reliable, valid evaluations of residents' and students' skills. As long as these patients are well-trained, such critiques are possible with minimal supervision by the program director or faculty member. Residents, interns, and students report having positive experiences with standardized patients because they know that these patients are actually instructors. Thus, residents, interns, and students are not intimidated or embarrassed by their mistakes. ${ }^{13,14}$ Likewise, these patients have expressed a great deal of satisfaction with their participation in these programs.

\section{Objective structured clinical examination}

A standardized method to assess clinical skills in a performance-based format, the objective structured clinical examination (OSCE) is designed using "stations" similar to those in a pathology practicum. ${ }^{15,16}$ At each station, both clinical knowledge and skills are measured using standardized patients or computer simulations. The OSCE approach makes it possible for program directors to evaluate how well residents, interns, and students perform. Such performance skills are difficult to measure using standardized written examinations.

However, part of the OSCE station can include written examination questions to evaluate problem-solving skills. For example, one OSCE station can be used to evaluate the skills necessary to take a cardiac history and to conduct a cardiac examination. Direct observation of the standardized patient interacting with the participants can be recorded using a detailed evaluation form.

A different station may feature another evaluation method, such as Folstein's Mini-Mental Status Examination or the CAGE questionnaire. The program director or selected faculty member should design the OSCE station, including the problem-solving activities, clinical skills, and the standardized patient.

\section{Comments}

The key to successfully incorporating any of the four methods outlined herein is to make patients an integral part of the educational program. Patients can be used effectively in training osteopathic medical students, interns, and residents. They provide a perspective on the healthcare experience that is often overlooked. As such, their involvement provides important learning opportunities for physicians-in-training and empowers patients with a greater sense of control over their own healthcare. Furthermore, these important contributions to osteopathic medical education can be made with only minimal financial expenditures.

\footnotetext{
References

1. Osler W: On the need of a radical reform in our methods of teaching senior students. Medical News 1903; 82:49-63.

2. Payson HE, Barchas J: A time study of medical teaching rounds. N Engl J Med 1965; 273:1468-1471.

3. Collins GF, Cassie JM, Daggett, CJ: The role of the attending physician in clinical training. $J$ Med Educ 1978;53:429-431.

4. Linsfors EW, Neelon FA: The case for bedside rounds. $N$ Engl $J$ Med 1980;303:1230-1233.

5. Medio FJ, Wilkerson L, Maxwell JA, et al: Improving teaching
} 
rounds: Action research in medical education. Proc Ann Conf Res Med Educ 1984;23:283-288.

6. Medio FJ: The patient as teacher. J Med Educ 1985;60:63-65.

7. Barrows HS, Abrahamson S: The programmed patient: A technique for appraising student performance in clinical neurology. $J$ Med Educ 1964;39:802-805.

8. Stillman PL, Ruggill JS, Rutala PJ, et al: Patient instructors as teachers and evaluators. $J$ Med Educ 1980;55:186-193.

9. Kretzschmar R: Evaluation of the gynecology teaching associate: An educational specialist. Am J Obstet Gynecol 1978;131:367373.

10. Stillman P, Regan MB, Philbin M, Haley HL: Results of a survey on the use of standardized patients to teach and evaluate clinical skills. Acad Med 1990;65:288-292.

11. Stillman P, Swanson DB: Ensuring the clinical competence of medical school graduates through standardized patients. Arch Intern Med 1987; 147:1049-1052.

12. Barrows $\mathrm{H}$, Williams $\mathrm{R}$, Moy $\mathrm{R}$ : A comprehensive performancebased assessment of fourth-year medical students' clinical skills. $J$ Med Educ 1987;62:805-809.

13. Stillman PL, Sabers D, Redfield D: Use of paraprofessionals to teach interviewing skills. Pediatrics 1976;57:769-774.

14. Stillman PL, Regan MB, Swanson DB, et al: An assessment of the clinical skills of fourth year students at four New England medical schools. Acad Med 1990;65:320-326.

15. Hart I: The objective structured clinical examination, in Lloyd J, Langsley D (eds): How to Evaluate Residents. Chicago, Il, American Board of Medical Specialties, 1980.

16. Kowlowitz V, Moole AJ, Sloane P: Implementing the objective structured clinical examination in a traditional medical school. Acad Med 1990;65:345-347. 